\title{
RIGHT VENTRICULAR HYPERTROPHY OF UN- KNOWN ORIGIN: SO-CALLED PULMONARY HYPERTENSION
}

\author{
BY \\ S. DE NAVASQUEZ, J. R. FORBES, AND H. E. HOLLING \\ From the Department of Pathology, Guy's Hospital Medical School \\ Received March 12, 1940
}

The following three cases are reported since they provide an opportunity for further defining the condition that has been termed primary pulmonary arteriosclerosis. It may be difficult to distinguish clinically from cardiac disease secondary to long-standing pulmonary disease. Brenner (1935) states that : " before the diagnosis of primary pulmonary arteriosclerosis is made, all the factors commonly (though perhaps erroneously) thought to cause secondary pulmonary vascular sclerosis must be absent and there must be marked hypertrophy of the right ventricle." He collected 16 cases, verified at autopsy, that satisfied these criteria; but few were fully investigated, particularly in regard to the relative weight of the right and left ventricles, on which the diagnosis ultimately depends. Lewis (1913-14) has shown that estimates of ventricular hypertrophy in the absence of accurate measurements may be fallacious, and has devised a method for determining the relative degree of hypertrophy of the ventricles by careful dissection and separate weighing. His method has been adopted in the present study, and his series of normal ratios of the relative weights of the ventricles have provided the standard by which the degree of right ventricular hypertrophy has been assessed.

Materials and Methods.-The hearts were severed from the parietal pericardium and great vessels and the chambers were freed from clot and then weighed. After preservation in 10 per cent formalin followed by 70 per cent spirit, the ventricles and septum were dissected from the rest of the heart and weighed separately, according to the method of Lewis. The weight of the left ventricle divided by that of the right provided the $L / R$ ratio.

Sections of the lungs were taken, at intervals of one centimeter, from the hilum to the periphery, and stained with hæmatoxylin and eosin and with Weigert's and Van Gieson's stains for elastic and fibrous tissues.

\section{REPORT OF CASE I}

A butler, aged 55, was admitted to Guy's Hospital complaining of shortness of breath and cough. His father had died at the age of 70 and had always been 


\section{S. DE NAVASQUEZ, J. R. FORBES, AND H. E. HOLLING}

" chesty" ; there was no other family history of heart or lung disease. He had a wife, who was well, but no children.

He was born in India. There was no history of cardiac disease, but for the past few years he had been "chesty and bronchial." Twelve days before admission he complained of shortness of breath and coughing, of swelling of the ankles and abdomen, and of loss of appetite. Four similar attacks previously had improved with rest in bed, but on this occasion rest did not benefit his condition.

On admission, he was very dyspnœic and showed venous pulsation in the neck and marked œdema of the ankles. The temperature was $98^{\circ} \mathrm{F}$. and the respirations were 25 a minute. The pulse was 120 and regular in force and rhythm. The blood pressure was $120 / 72 \mathrm{~mm}$. The chest showed very little respiratory movement and a few râles were heard. The abdomen contained free fluid. Venesection of 300 c.c. was performed and 500 c.c. of clear fluid were withdrawn from the abdomen.

He gradually sank into coma and died on the night of admission before he could be more fully investigated.

Autopsy (P.M. No. 104/1935)

A middle-aged male of medium build and good musculature, showing bilateral œdema of the lower extremities as far as the knees.

Cardiovascular System.-The pericardial sac was distended by an excess of clear yellow fluid and there were " milk patches" over the right ventricle. The heart was greatly enlarged, more of the enlargement being right-sided. The myocardium of the right ventricle was three to four times its normal thickness; that of the left ventricle and both auricles showed no abnormality. The myocardium was of normal colour and texture throughout. The tricuspid and pulmonary valves were very dilated, measuring respectively 17.3 and $11.6 \mathrm{~cm}$. in circumference ; they were otherwise normal. The mitral and aortic valves showed slight atheroma, but were otherwise normal. The coronary arteries showed slight fatty atheroma in the beginning of their course, without any appreciable alteration in the lumen. The aorta was of moderate elasticity and uniform diameter and showed patchy atheroma, becoming calcified and ulcerated near the bifurcation. The pulmonary artery was normal, apart from dilatation and slight atheroma in streaks in the main branch. The pulmonary arterial tree was dissected as far as the arteries measuring $2 \mathrm{~mm}$. in diameter, but no abnormality was found. The pulmonary veins were normal. There were no developmental abnormalities present in the heart, aorta, or pulmonary artery.

The weight of the heart, in toto, free from clot and including the epicardial fat, auricles, and ventricles, was $650 \mathrm{~g}$. The left and right ventricles, excluding the septum, weighed 140 and $165 \mathrm{~g}$. respectively, and the ratio of left to right was 0.84 (normal $\mathrm{L} / \mathrm{R}$ ratio $=1 \cdot 79$ ).

Respiratory System.-The larynx, trachea, and bronchi were normal. The pleural cavities were dry and the pleuræ showed bilateral superficial apical scarring, but were otherwise normal. The right and left lungs weighed 750 and $650 \mathrm{~g}$. respectively, and both showed anterior marginal emphysema of moderate degree and congestion at the bases. Otherwise the lungs were normal.

Histology of Lungs. - The alveoli were of normal size and air-containing. An occasional heart failure cell was present, and at the bases the alveolar walls were irregularly thickened by capillary congestion. Acute or chronic inflammatory disease was absent. The arteries, of $1 \mathrm{~cm}$. to $2 \mathrm{~mm}$. in external diameter, showed crescentic thickening of the intima by varying degrees of atheroma ; though the elastic tissue of 
the media was conspicuous, it was impossible to be certain that it was increased. The arteries of less than $2 \mathrm{~mm}$. in diameter were devoid of intimal changes and the media appeared normal. No hyaline necrosis of the vessel wall was seen.

Alimentary System.-The only abnormality was in the stomach, which showed a large chronic ulcer measuring $3 \times 2 \mathrm{~cm}$. on the lesser curvature, $5 \mathrm{~cm}$. from the pylorus. One litre of clear fluid was present in the peritoneal cavity. The liver weighed $1600 \mathrm{~g}$. and was normal in size and shape and showed venous congestion. The gall bladder, biliary ducts, and pancreas were normal, as was the histology of the liver and pancreas.

Lymphatic System.-The spleen weighed $200 \mathrm{~g}$., and showed a firm, congested pulp. The mesenteric, cervical, and mediastinal lymph glands were normal. On section the spleen was congested and showed hyaline vascular change in the arterioles.

Urinary System.-Each kidney weighed $200 \mathrm{~g}$. and was normal in size and shape with a smooth surface and loose capsule. The cortical parenchyma was of normal width and pattern. The pyramids were congested and firmer than usual in consistency. The pelves, ureters, and bladder and the prostate and testes were normal. On section the glomerular and intertubular capillaries were moderately congested. The arteries and arterioles were normal. The parenchyma appeared normal.

In this case and in the two that follow, both adrenal glands and the thyroid were normal, to naked eye and on section. The central nervous system was not examined in any of the three cases.

\section{REPORT OF CASE 2}

A shop assistant, aged 30, was admitted to Guy's Hospital complaining of shortness of breath. His father had died, aged 48, with thrombosis of the legs ; his mother was alive and well. His only sister had died of pulmonary tuberculosis when 19. He was married and had one son.

He had always enjoyed good health, and was examined for insurance two years before admission and passed fit. There was no history of rheumatism.

One year previously he suddenly became aware that he was short of breath on such slight exertion as running across the road, so that he had to stop and proceed slowly. At this time he noticed that he felt unusually tired after his work. A few weeks later, on getting up at night to attend to his young child, he felt dizzy, fell to the ground, and was unconscious for several minutes. $\mathrm{He}$ had two further attacks of unconsciousness. In the first, whilst running for a train, he felt dizzy and thought he was going to faint ; he grabbed a railing, but fell down unconscious and was aroused a minute later by someone speaking to him. A third attack occurred six weeks before admission, whilst he was sitting down after having brought some coal upstairs. There were other minor attacks of dizziness, but without loss of consciousness.

For a few months before admission he had had epigastric pain and diarrhœa, and for the last week had vomited all except light foods. For a month he had had an unproductive cough, and had been sleeping badly. He had been under medical care for six weeks, and for a week had been having digitalis, which was stopped two days before entering the hospital.

On admission, he was cyanosed and restless, but dyspnœa was not marked. Venous pulsation was absent in the neck. The temperature was $95^{\circ} \mathrm{F}$. and respirations 20 a minute.

On physical examination, the pulse was regular in force and rhythm over 
short periods of a minute or so, but for the space of a few beats the rate would suddenly rise from $40-50$ to $80-90$ a minute. On palpation of the apex, the rate of the heart was found to be constant at 80-90 a minute, a powerful impulse alternating with a weaker one and only the more powerful being transmitted to the pulse. Occasionally for a few beats all impulses at the apex were of equal strength and transmitted to the wrist. The apex beat was just under the nipple in the fifth intercostal space, and the heart was not enlarged to percussion. A systolic murmur was heard at the apex, but no diastolic murmur could be detected. The blood pressure was $125 / 95 \mathrm{~mm}$. The liver was just palpable and tender. There was no œdema or ascites. The spleen was not palpable.

Nothing abnormal was detected in the respiratory or nervous systems.

The day after admission the heart was beating at 80-90 a minute, the impulses being regular and of equal amplitude and all transmitted to the wrist. There was an occasional extrasystole, and at other times several of these in quick succession would precede a temporary return to the cardiac rhythm found on admission. An electrocardiogram taken on this day confirmed pulsus bigeminus and showed right axis deviation, inversion of $T_{2}$ and $T_{3}$, and a depression of the iso-electric period after the QRS complex, suggestive of the effects of the digitalis therapy.

Early the following morning he was very restless, and on trying to get out of bed felt dizzy and said he lost consciousness. He was dazed and confused for a short time afterwards, but was not dyspnœic, and recovered quickly from this attack. When examined, the rate of both pulse and apex beat was 90 a minute. That evening there was a return to the cardiac rhythm present on admission ; he became restless and more cyanosed and despite oxygen therapy died the same evening, three days after admission.

\section{Autopsy (P.M. No. 53/1938)}

A young male of slight build, of good nourishment, with no external abnormalities. There was no subcutaneous œdema.

Cardiovascular System.-The pericardial sac contained a slight excess of clear yellow fluid. The visceral pericardium showed numerous sub-epicardial petechiæ along the course of the coronary vessels, on both the anterior and posterior surfaces. The heart was extremely enlarged and globular in shape, most of the enlargement being due to hypertrophy of the right ventricle. The myocardium of the right side was thicker than that of the left, but was of normal colour and texture throughout. The tricuspid and pulmonary rings measured 16.0 and $10.5 \mathrm{~cm}$. in circumference, and were very dilated, but the valves were otherwise normal. The mitral and aortic rings were 11.5 and $7.5 \mathrm{~cm}$. in circumference and the valves were normal. There were no endocardial abnormalities. The coronary arteries were of equal size and were free from atheroma. The aorta was of normal elasticity and dimensions throughout and free from atheroma. There were no developmental abnormalities and the ductus arteriosus was closed. The pulmonary artery, throughout its branches, as far as the periphery of the lung, was dilated and showed yellow fatty atheroma in streaks and plaques. The wall was not appreciably thickened, though its branches throughout both lungs were more prominent than:normal and slightly rigid. The pulmonary veins were normal. The venæ cavæ and hepatic veins were dilated, otherwise normal.

The weight of the heart in toto was $530 \mathrm{~g}$. The right and left ventricles, excluding the septum, weighed 153 and $133 \mathrm{~g}$. respectively, and the ratio of left to right was $0 \cdot 87$.

The histology of the heart was normal. 
Respiratory System.-The larynx, trachea, and bronchi were normal. The pleural cavities each contained a few c.c. of clear fluid and the pleural membranes were normal throughout except for very superficial bilateral apical scarring. The right and left lungs weighed 620 and $540 \mathrm{~g}$. respectively, and were of normal shape and size, homogeneous in colour, air-containing throughout, and of normal consistency. The most conspicuous feature in the lungs was the prominence of the dilated atheromatous pulmonary arteries, which extended as far as the periphery. The tracheo-bronchial lymph glands were slightly pigmented, otherwise normal.

Histology of Lungs.-All the sections taken showed some dilatation of the capillaries, but the alveolar spaces were air-containing and devoid of any abnormality. The larger branches of the pulmonary artery from $1 \mathrm{~cm}$. to $3 \mathrm{~mm}$. in external diameter showed irregular thickening of the intima by atheroma, but the media appeared normal. The arteries of lesser calibre than $3 \mathrm{~mm}$. were devoid of intimal changes, while the media appeared thickened by hypertropy, being 20 per cent of the external diameter ; but since the media in arteries of this size varies from 6 to 32 per cent of the diameter with a mean of 16 per cent (Brenner), it is doubtful whether 20 per cent is indicative of medial hypertrophy.

Alimentary System.-The pharynx and œesophagus were congested. The stomach was greatly distended, the mucous membrane was congested, and the rugæ were thickened, but there was no ulceration or scarring. The rest of the alimentary tract and the peritoneum were normal. The liver weighed $1600 \mathrm{~g}$. and was just enlarged, with a slightly granular capsular surface that was firmer than normal in consistency. The cut surface was uniformly mottled by passive venous congestion, but was otherwise normal. The gall bladder, biliary tract, and pancreas were normal. On section the liver showed dilatation and congestion of the sinusoids and central venules, but the parenchyma appeared normal ; the pancreas was normal.

Lymphatic System.-The spleen weighed $110 \mathrm{~g}$. and was normal, except for some hyaline vascular change on section.

Urinary System.-Each kidney weighed $110 \mathrm{~g}$. and was of normal size and shape, with smooth surface and loose capsule. The parenchyma was of normal colour, width, pattern, and consistency. The pelves, ureters, bladder, prostate, and testes were normal. On section the kidneys were congested, but otherwise normal.

\section{REPORT OF CASE 3}

A leather dresser, aged 49, was first admitted to Guy's Hospital in February, 1937, complaining of shortness of breath.

Dyspnœa had first been observed by the patient after an attack of influenza in December, 1936. It became rapidly worse, and soon he was unable to hurry even a few yards to catch a bus. At the same time he began to complain of constant precordial pain, uninfluenced by exertion or by the taking of food, but aggravated by deep breathing. For many years he had had a chronic productive cough, which had increased since the onset of his illness. He had never coughed up blood. Apart from this cough, he had always enjoyed good health.

On admission he was orthopnœic and deeply cyanosed. Clubbing of the fingers and toes was present. The pulse rate was about 100 per minute, and the respiration rate varied between 30 and 50 per minute. The temperature was normal. There was no œdema and the venous pressure was not increased. The heart was clinically and radiologically slightly enlarged, but presented no other abnormality. The blood pressure was 104/74 mm. Movement of the chest was poor, and air entry diminished, particularly at the bases, where 
rhonchi were present. The liver was just palpable and somewhat tender. No other abnormality was apparent on clinical examination.

Examination of the blood showed a hæmoglobin percentage of 125 , $6,600,000$ red cells per c.mm., and 9300 white cells per c.mm. All the cells appeared normal. The erythrocyte sedimentation rate was $2 \mathrm{~mm}$. in the first hour. Examination of the urine showed no abnormality. The blood Wassermann and Kahn reactions were negative. Radiography of the chest revealed (erroneously, as was subsequently shown) paradoxical movement of the right hemi-diaphragm, and because of this finding a diagnosis of paralysis of the right phrenic nerve, due to carcinoma of the bronchus, was made.

However, by March he was able to return home and gradually got well enough to resume his work in April. He remained well, putting on a good deal of weight, until November, when his dyspnœa suddenly returned and became rapidly worse.

He was then re-admitted to Guy's Hospital, the clinical features being substantially the same as before, though the cyanosis and dyspnœa were not so prominent. Electrocardiography showed marked right axis deviation, with low voltage, and flattening of $\mathrm{T}_{3}$. An X-ray of the chest showed slight widening of the mediastinum and some enlargement of the pulmonary artery. The previous finding of paradoxical movement of the right hemi-diaphragm was confirmed during normal breathing, but on deep inspiration normal movement took place.

The diagnosis was considered to lie between "Ayerza's disease" and carcinoma of the bronchus. In view of the latter possibility a course of deep $\mathrm{X}$-ray therapy was given, after which the patient was discharged in January 1938.

He remained well and at work for several months until February, 1939, when the dyspnœa returned and rapidly grew incapacitating. $\mathrm{He}$ was readmitted in March in a very distressed state, with marked orthopnœa and severe cyanosis, but without venous engorgement and with only very slight œdema of the ankles. There was no pyrexia and the pulse rate was regular at about 100 per minute. Respirations varied between 30 and 60 per minute. The blood pressure was $120 / 72 \mathrm{~mm}$. The apex beat could be felt five and a half inches from the mid-line in the fifth intercostal space, and no abnormality was apparent on auscultation of the heart. Movement of the chest was slight, but apart from widespread rhonchi no clinical abnormality was present. The liver was not palpable. Examination of the urine showed no abnormality.

An X-ray of the chest revealed enlargement of the heart (transverse diameter $17 \mathrm{~cm}$. in a chest of $28 \mathrm{~cm}$.). The pulmonary artery and conus of the right ventricle were very prominent. The pulmonary arterial tree was well marked, but apart from this the lung fields were normal. An electrocardiogram showed very little change from that of a year before. Blood circulation times were also measured, the arm-to-lung time (paraldehyde) being 10 seconds and the armto-tongue time (decholin) 15 seconds; these figures lie within the normal range.

On the diagnostic grounds enumerated below, the case was considered to 
be one of primary pulmonary hypertension. Treatment was carried out in the oxygen tent. During the next few weeks the clinical condition fluctuated considerably, but some degree of dyspnœa and cyanosis was always present. Death occurred suddenly after four weeks in hospital.

\section{Autopsy (P.M. No. 138/1939)}

An elderly obese male of hypersthenic build, with barrel-shaped chest and wide intercostal angle. The fingers were clubbed and the ankles slightly œdematous.

Cardiovascular System.- The pericardium was slightly adherent to the right pleura by a few delicate fibrous bands. The sac and contents were normal except for a "milk patch" on the anterior surface of the right ventricle and a few petechiæ along the coronary sinus. The heart was globular in shape and much enlarged, due to great hypertrophy of the right ventricle. The myocardium of the right ventricle was two to three times the normal thickness, with hypertrophied columnæ carneæ and papillary muscles. That of the left ventricle and auricles was normal. The myocardium was of uniform colour, texture, and consistency. All the chambers were dilated and filled with post-mortem clot. The tricuspid and pulmonary rings were dilated and measured 13.5 and $10 \mathrm{~cm}$. in circumference, but the cusps were normal. The mitral and aortic rings were 11 and $7.5 \mathrm{~cm}$. and both valves were normal, apart from fatty atheroma of the anterior cusp of the former. The coronary arteries were of equal size and showed slight fatty atheroma at the beginning, but their lumina were not narrowed and were normal and patent throughout. The aorta was of normal elasticity and width, and showed a few patches of atheroma in the sinus of Valsalva, in the arch, and in the abdominal portions only. The pulmonary artery was uniformly dilated as far as the first division. The second branches of the pulmonary artery were more conspicuous than normal and showed patches of fatty atheroma. The remaining branches as far as those of 2 to $4 \mathrm{~mm}$. diameter appeared normal. There were no developmental abnormalities in the heart or great vessels.

The heart weighed $630 \mathrm{~g}$. The right and left ventricles, excluding the septum, weighed 162 and $129 \mathrm{~g}$. and the $\mathrm{L} / \mathrm{R}$ ratio was 0.80 .

Respiratory System.-The larynx, trachea, and bronchi contained frothy mucus and the mucous membrane was congested and slightly granular and covered by a delicate fibrinous exudate. The left pleural cavity was dry and the pleura was normal throughout. The right pleural cavity was obliterated over the upper lobe and showed a few basal pleuro-pericardial fibrous adhesions. Elsewhere it was normal. The right and left lungs weighed 1000 and $800 \mathrm{~g}$. respectively and were of normal size and shape. There was slight bullous emphysema along the anterior margins of both upper lobes, and the remainder of the lungs was slightly congested and œdematous, but of normal consistency and air-containing throughout. The bronchi were of normal diameter and, apart from slight congestion of the mucous membrane, were normal and free from inflammatory exudate. There was no evidence of acute or chronic inflammation in either lung. The tracheo-bronchial lymph glands were pigmented, but otherwise normal.

Histology of the Lungs.-The capillaries throughout the lung were engorged and the alveoli air-containing and devoid of cells. No abnormality could be detected in the arteries of $1 \mathrm{~cm}$. to $0 \cdot 2 \mathrm{~cm}$. in diameter. In some sections the smaller arteries were dilated; in others they appeared constricted. There was no inflammatory disease.

Alimentary System.-No abnormality was detected. The liver weighed $2100 \mathrm{~g}$. and was enlarged, with smooth surface and rounded edges. The cut surface was uniformly pale, with slight accentuation of the normal lobularity, and on section showed dilatation of the sinusoids. The gall bladder contained 50 c.c. of concentrated bile, which flowed freely, and the mucous membrane contained cholesterol deposits. The biliary passages and pancreas were normal. 
Lymphatic System.-The spleen weighed $300 \mathrm{~g}$. and was enlarged, with smooth capsule and a firm, uniformly congested pulp ; on section it showed hyaline vascular change only. The cervical, mediastinal, mesenteric, and inguinal lymph glands were normal.

Urinary System.-The right and left kidneys weighed 220 and 210 g. respectively, and were enlarged but of normal shape. The surfaces were smooth, with loose capsules. The cortices were of normal width and the vascular pattern was accentuated. The boundary zones were sharply defined and the pyramids deeply congested. The parenchyma was firmer than normal. The pelves, ureters, and bladder were normal, as were the prostate and testes. On section the kidneys were slightly congested, but were otherwise normal.

\section{Clinical Considerations}

From the study of these cases and those previously reported the chief points in the diagnosis of primary pulmonary hypertension would appear to be as follows :

1. There is central cyanosis, with which may be associated polycythæmia and clubbed fingers.

2. Dyspnœa may be the presenting symptom, but does not become extreme.

3. There is hypertrophy of the right ventricle, which sometimes may be demonstrable only by $\mathrm{X}$-ray examination.

4. Radiological evidence of dilatation of the pulmonary artery and of the right ventricular conus is present. This is probably the most important clinical finding, as it is not present to the same degree in heart failure secondary to lung disease.

5. There is no clinical, radiological, or pathological evidence of serious disease of the lung parenchyma.

6. The second pulmonary sound may be accentuated, but otherwise no signs of organic heart disease are present.

7. Electrocardiography shows right axis deviation and flattening or inversion of the $\mathrm{T}$ waves in leads II and III.

8. Increase of the systemic venous pressure and œdema occur only in the late stages when the heart fails.

9. The systemic arterial blood pressure is not increased.

10. There is no evidence of syphilis.

The distinction between pulmonary hypertension and cardiac failure secondary to chronic lung disease may not always be easy to make, especially where there is a history of dyspnœa. But X-ray and electrocardiographic evidence of marked right-sided cardiac hypertrophy or preponderance is not commonly found as a result of emphysema (Parkinson \& Hoyle, 1937). On clinical evidence the first case might be regarded as one of "cor pulmonale," since the patient had been described as "bronchial and chesty" for some years before the onset of symptoms suggestive of cardiac failure. The slight changes found in the bronchi and lung parenchyma post-mortem, however, did not appear to be sufficient to account for the marked hypertrophy of the right heart and dilatation of the pulmonary artery. The third case was said to show clinical emphysema, but in view of the difficulty in diagnosing emphysema at 
the bedside and the slight extent of the emphysema at autopsy we feel that this clinical finding may be dismissed.

A clinical diagnosis of Ayerza's disease is sometimes made in this type of case, but as there is no generally accepted definition of what is meant by this term it is better avoided. Congenital heart disease or mitral stenosis may cause difficulty in diagnosis. In the absence of the usual signs of these conditions, excessive cardiac pulsation or the smallness of the aorta may be of importance in distinguishing congenital disease, and the marked vascular changes at the hila and enlargement of the left auricle in distinguishing mitral stenosis.

The disease appears to run a course of from five months to five years after the onset of symptoms, the average expectation of life being two years. Our patients survived twelve days, twelve months, and twenty-eight months after the onset of symptoms. No specific treatment for the condition has been suggested ; oxygen therapy appeared to benefit the third case, but such treatment can only be symptomatic.

It might be presumed that the second patient, a man of 30 years, would demonstrate the features of the disease in a clearer manner than the other two cases, in which arteriosclerosis might have been a complicating factor. This patient may be compared with the first case of Brenner, a boy of 11 years. The first symptom noticed by both was dyspnœa on exertion. Both were markedly cyanosed, and suffered from attacks of unconsciousness. It is probable that the condition produces no symptoms until the enlarged right ventricle begins to fail, but in some respects the early symptoms appear to differ from those usually seen in right heart failure. The dyspnœa observed in the early stages does not appear to progress with the course of the disease, and the presence of marked cyanosis with the absence of systemic venous engorgement is remarkable. The cyanosis is due to the inadequate oxygenation of the blood in the lungs, but the reason for this is obscure. The rate of blood flow through the lungs, as judged by the measurement of the circulation times, appears to be unaltered, and there is no evidence of vascular congestion in the lungs. Moreover, histological study of the lung fails to reveal any change in the alveolar wall which might impede the passage of oxygen through it. The diminished oxygen content of the arterial blood is probably a more important factor in the causation of the dyspnœa on exertion than the possible presence of circulatory failure. Since the ventilating powers of the lungs are inadequate even at rest, it is suggested that they would prove even more so with the increased demand of the body for oxygen during exertion. A further lowering of the arterial oxygen content would also explain the syncopal attacks, which in their clinical features may be compared to StokesAdams seizures, and may be regarded as evidence of cerebral anoxia.

\section{Pathological Findings}

The only anatomical feature that was striking and common to all three cases was the great hypertrophy of the right ventricle, indicated by the $L / R$ ratios 
of $0 \cdot 84,0 \cdot 87$, and 0.80 . The normal ratio given by Lewis (1913-14) is $1 \cdot 79$, while that for eight cases of uncomplicated mitral stenosis was $1 \cdot 0$, showing that the relative degree of right ventricular hypertrophy in the present condition exceeds that found even in mitral stenosis.

The degree of atheroma of the pulmonary arterial tree varied, being conspicuous in the second, moderate in the third, and slight in the first case, and bore no relationship to the degree of ventricular hypertrophy. There was no clinical evidence of systemic hypertension, and the slightness of the left ventricular hypertrophy and the pathognomic sign of hyaline or " fibrinoid " necrosis in the intralobular arteries and afferent arterioles of the kidney is also against the co-existence of systemic hypertension (Hadfield and Garrod, 1932).

The histological changes in the pulmonary blood vessels, apart from intimal atheroma, were insignificant. There was no intimal thickening, medial hypertrophy, or any of the changes that are found in the small arteries and arterioles of the systemic circulation when systemic hypertension is present. In this connection it may be pointed out that such changes occur mainly in the smaller muscular type of arteriole, which is absent in the lung, where even the smaller arteries down to $0.1 \mathrm{~mm}$. diameter are of the elastic type with a relatively thin media. There are no vessels in the pulmonary arterial tree comparable to the afferent arteriole in the kidney, and the absence of a susceptible vessel may be a possible explanation for the lack of such lesions in the present cases. The diameter of the arterial lumen and the ratio of the lumen to the vessel wall varied too much to be of any significance. In the first case there was no appreciable difference from the normal; in the second the arteries down to less than $0.1 \mathrm{~mm}$. in diameter were uniformly dilated; whereas in the third the degree of contraction varied in different sections. In fact, there were no structural changes that could be considered abnormal. Similarly, the parenchyma of the lung was devoid of any evident abnormality.

\section{PATHOGENESIS}

With regard to the atiology and pathogenesis of the condition, there is little to add to Brenner's statement : "In most cases the changes appeared to be those of ordinary atherosclerosis and to be non-inflammatory. Most authors have suggested that primary sclerosis is caused by pulmonary vascular hypertension either due to spasm of the pulmonary arterioles or to congenital narrowness of the pulmonary veins. There is no evidence in favour of either of these suggestions and the cause remains unknown." Since Brenner's articles, further cases of primary pulmonary arteriosclerosis have been published. Kaump and Dry (1938) reported one, in which no adequate reason for the hypertrophy of the right ventricle could be found, and Rothschild and Goldbloom (1938) recorded a case of " obliterating pulmonary arteritis" and right ventricular hypertrophy and considered that the condition was allergic, but in the absence of heart weights it is impossible to assess their significance. Seely (1938) reported a case of primary obliterative pulmonary sclerosis in which the heart weighed $390 \mathrm{~g}$. against a normal average of $303 \mathrm{~g}$. for a female of 68 (Bell and 
Hartzell, 1923-4) ; the lungs weighed 200 and $170 \mathrm{~g}$. and were emphysematous. In view of the possibility, so far not proven, that emphysema may cause right ventricular hypertrophy, it is possible that the hypertrophy in this case was secondary to the emphysema. Alexander et al. (1927) in a clinical study of 50 patients with true bronchial asthma, evident for at least five consecutive years and of an average duration of ten years, found that emphysema was present in all except one. Examination of the heart revealed three patients with " cardiac injury," and in two of these the cardiac lesion antedated the asthma. In view of the difficulty of estimating the degree of emphysema both clinically and pathologically, the relationship between it and right ventricular hypertrophy is still a matter for conjecture. Parkinson and Hoyle found that great enlargement of the right heart is rare in emphysema, having been seen in only four cases out of eighty ; they conclude that the cardiac symptoms and signs in emphysema are more likely to be due to an accompanying systemic hypertension than to the direct effect of emphysema on the heart. There is no experimental evidence to show that any diminution in the pulmonary capillary bed, such as might occur in emphysema, causes an increase in blood pressure in the right side of the heart. Dunn (1919) occluded large areas of pulmonary circulation by injection of starch or oil in the jugular veins of animals and showed there was no alteration of blood flow through the lungs or in the pressure in the right side of the heart.

The most conspicuous anatomical abnormality in the pulmonary circulation of these cases is the great hypertrophy of the right ventricle. Does this single anatomical fact justify the opinion that the hypertrophy is a physiological reaction to increased work, and is therefore analogous to the left ventricular hypertrophy in systemic hypertension? Whereas in the latter the ventricular hypertrophy is associated with characteristic lesions in the systemic arteries and arterioles, but is independent of the degree of arteriosclerosis, right ventricular hypertrophy is unassociated with any such comparable lesions in the smaller pulmonary arteries. An explanation of the lack of arteriolar changes may be that such changes in the systemic arteries are usually confined to the muscular type of artery, which is absent in the pulmonary circulation. The existence, therefore, of pulmonary hypertension is conjectural, and is not justified on analogy alone. If a name based on the morbid anatomy is required for this condition, "idiopathic right ventricular hypertrophy" would appear to be a suitable one, until such time as the condition may have acquired a proved ætiology. The term "pulmonary arteriosclerosis" is misleading, as the arteriosclerosis would seem inadequate to account for the ventricular hypertrophy.

\section{SUMMARY}

1. Three cases of severe right ventricular hypertrophy of unknown origin have been described.

2. The usually accepted causes of such hypertrophy due to disease of the heart and lungs have been excluded.

3. The clinical and pathological changes have been described and discussed. 
188 S. DE NAVASQUEZ, J. R. FORBES, AND H. E. HOLLING

4. It is suggested that the term "idiopathic right ventricular hypertrophy" should in future replace " primary pulmonary arteriosclerosis" or " hypertension," which have no foundation in fact.

\section{REFERENCES}

Alexander, H. L., Luten, D., and Kountz, W. B. (1927). J. Amer. med. Ass., 88, 882.

Bell, E. T., and Hartzell, T. B. (1923-4). J. met. Res., 44, 473.

Brenner, O. (1935). Arch. intern. Med., 56, 211, 457, 724, 976, and 1189.

Dunn, J. S. (1919). Quart. J. Med., 13, 46, 129.

Hadfield, G., and Garrod, L. P. (1932). Recent Advances in Pathology, London, 180.

Kaump, D. H., and Dry, T. J. (1938). Arch. intern. Med., 61, 1.

Lewis, T. (1913-14). Heart, 5, 367.

Parkinson, J., and Hoyle, C. (1937). Quart. J. Med., 6, 59.

Rothschild, M. A., and Goldbloom, A. A. (1938). Arch. intern. Med., 61, 600.

Seely, H. (1938). J. Amer. med. Ass., 110, 792. 